\title{
Ingestão de nutrientes e consumo voluntário em Red Rumped (Psephotus haematonotus) alimentados com ração comercial e sementes
}

\author{
OLIVEIRA, Júlia ${ }^{1}$; FERNANDES, Barbara ${ }^{1}$; MACHADO, Rodrigo²; MORENO, Tatiane ${ }^{3}$; ROCHA, \\ Chayane $^{4}$
}

\footnotetext{
${ }^{1}$ Graduanda em Zootecnia, UFPR

${ }^{2}$ Graduando em Medicina Veterinária, UFPR

${ }^{3}$ Zootecnista, Mestranda do Programa de Pós-graduação em Zootecnia UFPR

${ }^{4}$ Professora do Departamento de Zootecnia, UFPR

E-mail: julia.caroline.oliveira203@gmail.com
}

RESUMO: Devido à falta de informação sobre a ingestão de nutrientes das aves em cativeiro é comum o fornecimento de rações não especificas ou misturas de diversas sementes, podendo ocasinar doenças por deficiência nutricional, uma vez que esses animais comem seletivamente. $O$ objetivo deste trabalho foi analisar a ingestão voluntária e de nutrientes de dietas contendo ração e/ou sementes para periquito Red Rumped. Dessa forma, 21 aves foram distribuídas aleatoriamente em três tratamentos com sete repetições cada. Os tratamentos consistiram em: T1 - ração extrusada $(R E)+$ sementes de girassol $(G)$, alpiste $(A)$ e painço $(P)$; T2$R E+A+P$ e T3- RE. O estudo teve duração de 12 dias, sendo 5 de adaptação e 7 de coleta de dados. Diariamente, foi disponibilizado para as aves $59 \mathrm{~g}$ de cada item alimentar e, quantificado as sobras do comedouro e desperdício de alimentos. Foi estimada a ingestão de matéria seca, proteína bruta, extrato etéreo, cálcio e fósforo. Os dados de ingestão voluntária e de nutrientes foram submetidos à ANOVA e suas médias comparadas pelo Teste de Tukey (5\%). Verificou-se que as aves que receberam todos os itens alimentares (T1) (19,03 g/dia) ingeriram maior quantidade total de MS $(\mathrm{p}<0,001)$ em relação ao T3 $(10,26 \mathrm{~g} / \mathrm{dia})$. A ingestão de PB e EE foram maiores no T1 (2,85; 3,65 g/dia) quando comparado aos T2 (2,37; $0,59 \mathrm{~g} / \mathrm{dia})$ e T3 (1,36; $1,07 \mathrm{~g} / \mathrm{dia})$. O consumo mínimo recomendado de Ca foi suprido somente nas aves que receberam apenas ração (T3) (1,07 g/dia) e diferiu dos T1 e T2 (0,05; 0,04 g/dia). A ingestão de energia $(110,4 \mathrm{kcal} / \mathrm{dia})$ nas aves do T1 foi superior $(p<0,0001)$ em relação ao T2 $(79,97 \mathrm{kcal} / \mathrm{dia})$ e T3 $(45,05 \mathrm{kcal} / \mathrm{dia})$.

Palavras-chave: girassol; nutrientes; seletividade.

\section{INTRODUÇÃO}

Conhecido também como periquito do dorso vermelho, o Red Rumped (Psephotus haematonotus) é originário da Austrália, são dóceis e se relacionam bem tanto com sua própria espécie quanto com o ser humano. Embora esta ave tenha o verde como sendo sua coloração original, atualmente podem ser encontradas aves com penas de cores variadas, o que faz com que seja frequentemente usada como animal para ornamentação. A manutenção de psitacídeos em cativeiro deve ser feita de maneira exige cuidados relacionados ao manejo, ambiente, alimentação e nutrição. Entretanto, frente ao desconhecimento das necessidades nutricionais das aves e da desinformação dos proprietários quanto aos princípios básicos que os 
orientam na alimentação de suas aves, as doenças nutricionais são uns dos problemas mais prevalentes na clínica das aves (ULLREY et al., 1991).

A oferta de rações não específicas e mistura de diversas sementes como alpiste, amendoim e girassol são pratica comuns, podendo ocasionar inúmeras doenças por desequilíbrio ou deficiência nutricional dos alimentos ingeridos, uma vez que os pássaros comem seletivamente (LUMEIJA et al. 1996). Por mais que a preferência das aves seja por sementes, estas apresentam ausência ou baixa concentração de diversos nutrientes essenciais para a saúde da ave (SAAD et al., 2007; HARRISSON, 1998). A substituição no fornecimento de sementes pelas rações extrusadas muitas vezes não é bem sucedida, uma vez que aves são relutantes em aceitar a substituição de sementes ricas em gordura (ex:.girassol e níger) por ração (HARRISON, 1998). O objetivo desse trabalho foi quantificar - consumo voluntário e estimar a ingestão de nutrientes na espécie Psephotus haematonotus mantidos sob cuidados humanos e recebendo dietas contendo alimento completo (ração) e diferentes tipos de sementes.

\section{MATERIAL E MÉTODOS}

O projeto foi aprovado pelo Comitê de Ética ao Uso de Animais da Universidade Federal do Paraná (certificado 066 2017). Os experimentos foram conduzidos no Laboratório de Criação e Incubação de Animais Silvestres - LACRIAS, da Universidade Federal do Paraná - UFPR, localizado na Fazenda Experimental Canguiri. Com duração de 12 dias, sendo 5 para adaptação e 7 de coleta de dados. Para tanto, 21 aves da espécie de Red Rumped, pesados no inicio e ao final do experimento, foram alojadas individualmente em gaiolas do tipo voadeira, cada gaiola era equipada por dois poleiros de madeira, comedouros de cerâmica e bebedouro tipo nipple. $\mathrm{O}$ delineamento experimental foi inteiramente casualizado composto de três tratamentos com sete repetições cada, os quais consistiram em três diferentes dietas: T1) ração comercial extrusada de psitacídeos de pequeno de médio porte em manutenção - RE+ sementes de girassol - G (Helianthus annuus), alpiste (Phalaris canariensis) A e painço - $\mathrm{P}$ (Panicum miliaceum $)$; T2) $\mathrm{RE}+\mathrm{A}+\mathrm{P}$; T3) RE. Diariamente foi ofertado em comedouros individuais $59,0 \mathrm{~g}$ cada item alimentar. Para estimar a ingestão utilizou-se a expressão: ofertado - (sobras de comedouro + desperdício). Para uma maior estimar a ingestão de nutrientes, uma amostra de 100 gramas de cada semente ofertada às aves foi descorticada manualmente, para quantificar a proporção entre conteúdo intracelular e cascas e, assim analisar somente 0 material ingerido pelas aves. Todos os alimentos fornecidos as aves, inclusive suas porções (casca e conteúdo), foram analisados em laboratório para determinação dos teores de matéria seca, proteína bruta, extrato etéreo, matéria mineral, cálcio e fósforo segundo metodologia descrita pela AOAC (1995). A energia bruta foi determinada em bomba calorimétrica (Model 1261, Parr Instrument Co., Moline, IL). Os dados foram submetidos à análise de variância e suas médias comparadas pelo teste de Tukey ao nível de 5\% significância.

\section{RESULTADOS E DISCUSSÃO}

É possível observar que a ingestão de matéria seca (MS) em relação ao peso vivo (\%) e a ingestão total de MS foram maiores foram maiores nos tratamentos com oferta de sementes ( $\mathrm{T} 1$ e $\mathrm{T} 2)$ quando comparados ao das aves recebendo ração extrusada como único alimento. 
Foi observada diferença significativa para ingestão de proteína bruta entre os tratamentos, sendo possível verificar maior a ingestão total de PB nos tratamentos com fornecimento de sementes. A ingestão de extrato etéreo e fosforo foram iguais no T2 e T3, diferindo do T1 $(p<0,0001)$. $\mathrm{A}$ ingestão de $\mathrm{Ca}$ foi superior quando fornecida ração como fonte exclusiva de alimento, diferindo significativamente dos demais tratamentos. A energia bruta ( $\mathrm{kcal} / \mathrm{kg} / \mathrm{dia})$ ingerida pelas aves diferiu entre os três tratamentos, onde a ingestão no T1 $(110,40 \mathrm{kcal} / \mathrm{dia})$ foi significativamente maior quando comparado ao T2 $(79,97 \mathrm{kcal} / \mathrm{dia})$ e T3 $(45,05 \mathrm{kcal} / \mathrm{dia})$.

\begin{tabular}{|c|c|c|c|c|}
\hline & T1 & Т2 & T3 & $P$ \\
\hline MS/PV (\%) & $32,45^{a}$ & $27,51^{a}$ & $14,42^{b}$ & $<0,0001$ \\
\hline ITMS (g/ave/dia) & $19,03^{a}$ & $18,85^{a}$ & $10,26^{b}$ & $<0,0001$ \\
\hline ITPB (g de PB/MS/dia) & $2,85^{\mathrm{a}}$ & $2,37^{a}$ & $1,36^{b}$ & $<0,0001$ \\
\hline ITEE (g de EE/MS/dia) & $3,65^{a}$ & $0,59^{b}$ & $1,07^{b}$ & $<0,0001$ \\
\hline ITCa ( g de Ca/MS/dia) & $0,05^{b}$ & $0,04^{b}$ & $1,07^{a}$ & $<0,0001$ \\
\hline ITP (g de P/MS/dia) & $0,08^{a}$ & $0,05^{b}$ & $0,05^{b}$ & $<0,0001$ \\
\hline ITEB (kcal/kg/dia) & $110,40^{a}$ & $79,97^{b}$ & $45,05^{c}$ & $<0,0001$ \\
\hline
\end{tabular}

De acordo com as exigências nutricionais diárias recomendadas pela AAFCO (1998), a ingestão de PB (\%) e $\mathrm{P}(\%)$ pelas aves, atenderam as recomendações mínimas (Tabela 2). Neste estudo, as aves ingeriram $15,01 \%, 12,52 \%$ e $13,27 \%$ de proteína bruta e $0,43 \%, 0,29 \%$ e $0,45 \%$ de fósforo nos tratamentos 1, 2 e 3 , respectivamente, atingindo a ingestão mínima recomendada para tais nutrientes, com exceção do fosforo no T2. As aves apresentaram a ingestão de cálcio de 0,24\%, 0,22\% e 0,99\% para os tratamentos 1, 2 e 3, respectivamente, atingindo a recomendação de ingestão mínima de cálcio somente no tratamento com fornecimento exclusivo de ração. Foi possível verificar que as aves de T1 e T2 não foram capazes de ingerir o requerimento mínimo de cálcio frente à oferta livre de sementes por estas se tratarem de um alimento com baixa concentração desse elemento. A relação Ca: $P$ foi mantida próximo ao máximo recomendado somente com 0 fornecimento exclusivo de ração.

\begin{tabular}{|c|c|c|c|c|c|}
\hline & T1 & T2 & T3 & $\begin{array}{c}\text { Recomendado } \\
\text { Minimo* }^{*}\end{array}$ & $\begin{array}{c}\text { Recomendado } \\
\text { Máximo* }^{*}\end{array}$ \\
\hline PB (\%) & 15,01 & 12,52 & 13,27 & 12,00 & NR \\
\hline EE $(\%)$ & 19,45 & 3,22 & 10,45 & NR & NR \\
\hline $\mathrm{Ca}(\%)$ & 0,24 & 0,22 & 0,99 & 0,30 & 1,20 \\
\hline $\mathbf{P}(\%)$ & 0,43 & 0,29 & 0,45 & 0,30 & NR \\
\hline Ca: P & $0,56: 1$ & $0,76: 1$ & 2,18:1 & 1:1 & 2:1 \\
\hline
\end{tabular}

Na tabela 3, é possível observar a ingestão em matéria seca de ração, painço, alpiste e girassol dentro dos tratamentos 1 e 2. Quando o animal tem acesso a sementes, a ração é pouco consumida, já que a semente é muito palatável a eles. A preferencia pela semente de girassol ficou evidente no $\mathrm{T} 1$, os animais consumiram mais do que - dobro quando comparado as sementes de painço e alpiste. No T2, que não possuía o girassol, o consumo foi equilibrado tanto para o consumo de painço quanto de alpiste.

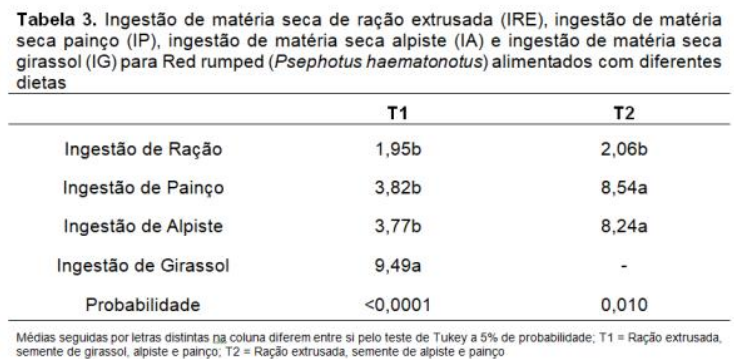

\section{CONCLUSÃO}

Com os resultados obtidos nesse trabalho, foi possível observar que:

1) a disponibilidade de sementes possibilitou que as aves escolhessem os itens alimentares que preferiam consumir, resultando na maior ingestão 
de alimento; 2) o consumo de semente foi muito maior em relação a ração; 3) a recomendação mínima de Ca só foi suprida nos animais que possuíam apenas a ração como item alimentar.

\section{REFERÊNCIAS}

Association of american feed control officials incorpora ted (AAFCO). Nutrition expert panel review: new ruler for feeding pet birds. Official Publication - Feed Management, Atlanta, v. 49, n. 2, 1998.

BENEZ, S. M. Aves: criação, clínica, teoria, prática: silvestres, ornamentais, avinhados. 4. ed. Ribeirão Pret: Tecmedd, 2004. 600p.

MACHADO, P. A. R.; SAAD, C. E. P. O futuro das racoes para aves ornamentais e silvestres no Brasil. Aves Revista Sul Americana de Ornitofilia, Belo Horizonte, v.3, p.37-40, 2000.
Agradecemos ao apoio da Fundação Araucária e da Coordenação de Aperfeiçoamento de Pessoal de Nível Superior - CAPES na realização do $3^{\circ}$ Workshop de Nutrição de Animais Selvagens.
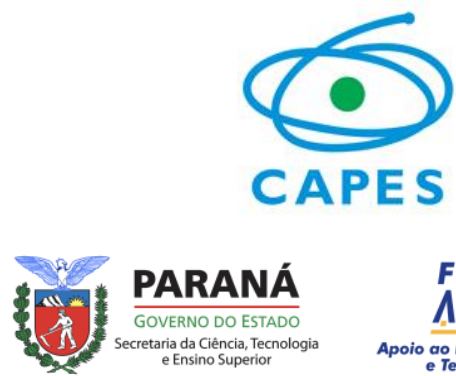

\section{PARANÁ}

GOVERNO DO ESTADO e Ensino Superior
Salén
FUNDACÃO ARAUCARII 